\title{
Predictors of spirometric test failure: a comparison of the 1983 and 1993 acceptability criteria from the European Community for Coal and Steel
}

\author{
S Humerfelt, G E Eide, G Kvåle, A Gulsvik
}

\begin{abstract}
Objectives-To identify, in this general population study, predictors of spirometric test failure on the 1983 and 1993 acceptability criteria from the European Community for Coal and Steel (ECCS). Methods-All men aged 30-46 years living in western Norway $(n=45380)$ were invited to join a cross sectional community survey. Respiratory symptoms, smoking habits, and marital status were found from self administered questionnaires, and measurements of forced expiratory volume in one second $\left(\mathrm{FEV}_{1}\right)$ and forced vital capacity (FVC) were performed with dry wedge bellow spirometers.
\end{abstract}

Results-Altogether 29611 subjects (65\%) participated in this survey. Spirometric recordings were obtained in 26803 of these (91\%) of whom $1.6 \%$ failed the 1983 criterion ( $\leqslant 300 \mathrm{ml}$ between the two highest FVC values) and $9.5 \%$ failed the 1993 criteria ( $\leqslant 5 \%$ or $100 \mathrm{ml}$ between the two highest $\mathrm{FEV}_{1}$ and the two highest FVC values). Spirometric failures on both criteria were more prevalent in never smokers, single men, and subjects with respiratory symptoms than in ever smokers, married, and asymptomatic subjects. Failure of the 1993 criteria increased with age and declining height. Morning cough and phlegm, breathlessness uphill, attacks of breathlessness, and wheezing were related to failure of the 1993 criteria after adjustment for demographic variables and smoking, whereas only breathlessness uphill was related to failure of the 1983 criterion.

Conclusions-In men aged 30-46 years, spirometric test failures on both the 1983 and 1993 ECCS acceptability criteria occurred more often in never smokers than in smokers and ex-smokers after adjustment for other covariables. Spirometric test failure with the 1993 criteria also varied with height and most respiratory symptoms. The higher failure rates found in non-smokers, in shorter, and in single men could be due to late compression of the airways, smaller lung volumes, and poor general health, respectively.
(Occup Environ Med 1995;52:547-553)

Keywords: spirometric test failure; epidemiology; general population survey

Standardised procedures have been developed to ensure maximum validity and minimal variability of recordings from forced expiratory volume manoeuvres. ${ }^{12}$ According to the 1983 recommendations from the European Community for Coal and Steel (ECCS) up to eight repeated measurements should be performed to obtain three acceptable recordings with a difference of $\leqslant 300 \mathrm{ml}$ between the two highest FVC values. ${ }^{1}$ In their 1993 update, as in the 1987 update from the American Thoracic Society (ATS), the two highest values for both forced expiratory volume in one second $\left(\mathrm{FEV}_{1}\right)$ and forced vital capacity (FVC) should not differ by more than 5\% or $100 \mathrm{ml}$, whichever is the greater. ${ }^{23}$ These new criteria are thus stricter than the 1983 criterion for subjects with FVC values $<6.001$.

Several studies in occupational groups have found increased respiratory morbidity and mortality in subjects with recordings outside defined criteria than in those within. ${ }^{45}$ Subjects with obstructive airway disease have greater variability in ventilatory function than healthy subjects ${ }^{6}$ and are therefore less able to meet the defined acceptability criteria. Furthermore, it might be tiring for subjects to continue to perform maximal expiratory manoeuvres to fulfil the 1993 criteria. $^{7}$

Although it is generally accepted that subjects with unsuccessful spirometry are more at risk of ill health, ${ }^{8}$ limited knowledge is available on the characteristics of these subjects from general population studies. Limited knowledge is also available on the consequences of the new stricter acceptability criteria in general population studies.

In this cross sectional study of men aged $30-46$ the objectives of these analyses were to identify predictors of spirometric test failure on the 1983 ECCS acceptability criterion related to demographic characteristics, smoking habits, and respiratory morbidity. At the same time we wanted to identify characteristics in subjects who were unable to fulfil the 1993 criteria. 
Subjects and methods STUDY POPULATION

The source population included all men living in the city of Bergen and 34 rural municipalities in western Norway (Hordaland county and Sauda municipality in Rogaland county) on 1 January 1988, born between 1944 and 1958. This comprised 45723 inhabitants. The source population was obtained from the central population registry in Norway, which was updated every three months through the local population registry in each municipality. Eligible subjects (45 380) were obtained after all deaths and migrations in each municipality had been excluded. ${ }^{9}$

\section{STUDY DESIGN}

From October 1988 to September 1990 all eligible subjects were invited once to a screening examination at the Occupational Lung Function Survey in western Norway. Each subject received a postal invitation with a self administered questionnaire and a pamphlet on occupational exposure. A mobile unit from the National Health Screening Service visited each municipality and performed measurements of spirometry, height, and weight, and took a miniature chest $x$ ray film of all the participants. Completed questionnaires were handed in during the visit. The survey was approved by the Regional Committee of Medical Research Ethics.

\section{QUESTIONNAIRE}

The questionnaire elicited information on smoking habits, occupational exposures, respiratory symptoms, and physician's diagnoses. Never smokers were men who had never smoked daily and ex-smokers included those who had stopped smoking before screening. ${ }^{9}$ The wording of the six questions on respiratory symptoms considered in this survey were as follows: (a) do you usually cough in the morning (morning cough)?; (b) do you usually have phlegm in the morning (morning phlegm)?; (c) have you had any chest illness of more than three weeks duration during the past two years (recurrent chest illness)?; (d) are you more breathless than subjects of the same age when walking uphill (breathlessness uphill)?; (e) do you have attacks of breathlessness (attacks of breathlessness)?; and ( $f$ ) do you ever have wheezing in your chest (wheeze)? The wording of the two questions on physician's diagnoses used in these analyses were: $(a)$ have you ever been treated by a physician or admitted to hospital for asthma (physician's diagnosis of asthma)?, and $(b)$ have you ever been treated by a physician or admitted to hospital for emphysema (physician's diagnosis of emphysema)? The alternatives for answering were "yes" or "no" for all questions and in addition "don't know" for the last two questions. Subjects who denied all eight of these questions were classified as asymptomatic.

\section{HEIGHT AND WEIGHT}

Standing height was measured to the nearest $\mathrm{cm}$ without shoes with heels and neck nearest the measure. Weight was measured to the nearest $0.5 \mathrm{~kg}$ without shoes and wearing trousers with empty pockets. Body mass index (BMI) was defined as weight divided by height $^{2}\left(\mathrm{~kg} / \mathrm{m}^{2}\right){ }^{10}$

\section{SPIROMETRY}

Forced expirations were recorded with three dry wedge spirometers (Vitalograph Smodel). The instruments were calibrated twice daily with a 1 litre syringe. ${ }^{11}$ The spirometric measurements were performed with the subject sitting upright with a nose clip, and with a minimum exhalation time of six seconds, unless there was an obvious plateau on the chart. Each subject performed up to eight repeated measurements until three acceptable forced expiration manoeuvres were obtained with the two highest FVC values reproducible within $300 \mathrm{ml} .^{1}$ The ATS recommendations on manoeuvre performance and end of test criteria were applied. ${ }^{2}$ The three highest measurements of FVC with their corresponding $\mathrm{FEV}_{1}$ were manually recorded in litres to nearest $50 \mathrm{ml}$ by the technician. The technician also coded the number of acceptable recordings, whether the subject failed to do satisfactory measurements, or was unwilling to do the test. Men aged $<40$ years were given priority over those aged $>40$ years if queues developed at spirometric testing. All FEV 1 and FVC values were corrected to body temperature and pressure saturated conditions (BTPS). Age and height standardised residuals of maximum values of $\mathrm{FEV}_{1}$ $\left(\mathrm{SFEV}_{1}\right)$ and FVC (SFVC) were used as variables of lung function. ${ }^{11}$ These were calculated by dividing the absolute residual (recorded minus predicted level) by the residual $\mathrm{SD}$ taken from the regression equation from the Norwegian reference population of healthy asymptomatic men. ${ }^{12}$

\section{TECHNICIANS AND QUALITY CONTROL}

The technicians were trained in standardised spirometry before the survey and received a written protocol. Supervision was given throughout the first two weeks of the survey and thereafter at regular intervals. After the spirometric recordings were entered into the data file quality control was maintained through computerised inconsistency programs to identify unacceptable values. These values were manually proof read and verified with the vitalogram charts.

\section{STATISTICAL METHODS}

All analyses were performed with the BMDP package. ${ }^{13}$ Unpaired $t$ tests were used to compare mean values. Differences between prevalences were tested by $\chi^{2}$ tests. A significance level of $\mathbf{P}=0.05$ (two tailed) was used for all the analyses unless stated otherwise. Multiple logistic regression analyses were used for binomial outcome variables. Categorical variables were introduced to the equations with the dummy variable technique. 
Table 1 Attendance and subjects with spirometry by age, marital status, and place of residence among all men born in 1944-58 living in 35 municipalities in western Norway, 1988-90

\begin{tabular}{llll}
\hline & $\begin{array}{l}\text { Eligible population } \\
n\end{array}$ & $\begin{array}{l}\text { Attenders } \\
(n=29611) \\
\%^{*}\end{array}$ & $\begin{array}{l}\text { Spirometry performed } \\
(n=26803) \\
\%^{*}\end{array}$ \\
\hline Age $(y): \dagger$ & & & \\
$30-34$ & 12860 & 62 & 59 \\
$35-39$ & 15135 & 65 & 60 \\
$40-44$ & 15036 & 68 & 58 \\
$45-46$ & 2333 & 67 & 60 \\
Marital status: $¥$ & & & \\
Single & 8710 & 57 & 53 \\
$\quad$ Married & 32572 & 70 & 63 \\
$\quad$ Divorced or separated & 3972 & 46 & 42 \\
Place of residence: & 22392 & 73 & 63 \\
$\quad$ Rural municipalities & 22988 & 58 & 56 \\
$\quad$ Urban municipality of Bergen & 45380 & 65 & 59 \\
Total & &
\end{tabular}

*Percentage of eligible population.

†Age in years to the nearest month of invitation to the survey. The additional 16 subjects were aged 29 years.

$\ddagger$ Marital status was missing in 31 subjects and 95 subjects were widowers.

\section{Results}

Altogether 29611 subjects (65\% attendance) participated in this survey (table 1). An additional 3\% (1301 subjects) returned answered questionnaires through the post. The attendance rate was lower $(P<0.01)$ in the age group $<35$ years than those aged $\geqslant 35$ years, lower $(P<0.01)$ in unmarried (single, divorced, or separated) than in married subjects, and lower $(P<0.01)$ in the city of Bergen than in the rural municipalities (table 1). Spirometric measurements were performed in $91 \%$ of the attenders (table 1 ). Attenders who performed spirometry were younger (mean (SD) 38 (4) years; $P<0.01$ ) than those who did not attempt spirometry (mean (SD) 40 (4) years). Both groups reported similar height, weight, smoking habits, and respiratory symptoms.

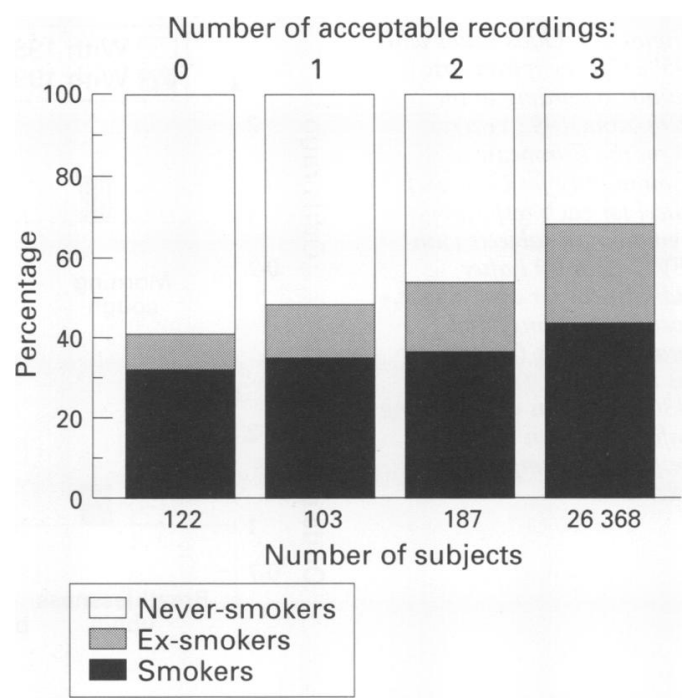

Figure 1 Smoking habits (\%) by number of acceptable tests according to the 1983 criterion from the European Community for Coal and Steel $(n=26780)$. Subjects who were unwilling to do the tests $(n=8)$ or who had missing information $(n=15)$ are excluded.

\section{CRITERION}

Only $1.6 \%$ of the subjects who performed spirometry failed the 1983 criterion (table 2) and included subjects with either two ( $\mathrm{n}=$ $187)$, one $(n=103)$, or no $(n=122)$ acceptable recordings (fig 1). An additional eight subjects were unwilling to do the test and 15 subjects had missing information.

Subjects with no acceptable recordings were shorter (mean (SD) 176 (7) cm; P < 0.001 ) than subjects with three, two, or one acceptable recordings $(179(6) \mathrm{cm})$ and weighed less $(76(13) \mathrm{kg} ; \mathrm{P}<0.05)$ than the other subjects $(79(11) \mathrm{kg}$ ).

Table 2 Smoking, marital status, respiratory symptoms, and standardised residuals of FEV (SFEV) and FVC (SFVC) by acceptability of spirometric recordings according to the 1983 and 1993 criteria from the European Community for Coal and Steel

\begin{tabular}{|c|c|c|c|c|c|c|}
\hline & \multicolumn{3}{|c|}{$\begin{array}{l}1983 \text { Criterion: all subjects with } \\
\text { spirometric recordings }(n=26803) \dagger\end{array}$} & \multicolumn{3}{|c|}{$\begin{array}{l}1993 \text { Criteria: subjects with FVC values } \\
\leqslant 6.00 l(n=25324)\end{array}$} \\
\hline & $\begin{array}{l}\text { Recordings within } \\
\text { the } 1983 \text { criterion }\end{array}$ & $\begin{array}{l}\text { Recordings outside } \\
\text { the } 1983 \text { criterion }\end{array}$ & $P$ value & $\begin{array}{l}\text { Recordings within } \\
\text { the } 1993 \text { criteria }\end{array}$ & $\begin{array}{l}\text { Recordings outside } \\
\text { the } 1993 \text { criteria }\end{array}$ & Pvalue \\
\hline $\begin{array}{l}\text { n (\%) } \\
\text { Smoking habits (\%): }\end{array}$ & $26368(98 \cdot 4)$ & $420(1 \cdot 6)$ & & $22907(90 \cdot 5)$ & $2417 \quad(9 \cdot 5)$ & \\
\hline $\begin{array}{l}\text { Smoking habits }(\%): \\
\text { Never smokers } \\
\text { Ex-smokers } \\
\text { Smokers }\end{array}$ & $\begin{array}{l}31 \cdot 5 \\
24 \cdot 7 \\
43 \cdot 9\end{array}$ & $\begin{array}{l}50 \cdot 6 \\
15 \cdot 0 \\
34 \cdot 4\end{array}$ & $\star \star$ & $\begin{array}{l}31 \cdot 0 \\
24 \cdot 6 \\
44 \cdot 3\end{array}$ & $\begin{array}{l}35 \cdot 7 \\
21 \cdot 5 \\
42 \cdot 8\end{array}$ & $\star \star$ \\
\hline Marital status (\%): & & & $\star \star$ & & & $\star \star$ \\
\hline $\begin{array}{l}\text { Married } \\
\text { Single } \\
\text { Divorced or separated }\end{array}$ & $\begin{array}{c}76 \cdot 8 \\
16 \cdot 8 \\
6 \cdot 3\end{array}$ & $\begin{array}{r}59 \cdot 9 \\
36 \cdot 3 \\
3 \cdot 8\end{array}$ & & $\begin{array}{r}77 \cdot 1 \\
16 \cdot 5 \\
6 \cdot 4\end{array}$ & $\begin{array}{r}70 \cdot 1 \\
23 \cdot 9 \\
6 \cdot 0\end{array}$ & \\
\hline Respiratory symptoms (\%): & & & & & & \\
\hline $\begin{array}{l}\text { Morning cough } \\
\text { Morning phlegm } \\
\text { Recurrent chest illness } \\
\text { Breathlessness uphill } \\
\text { Attacks of breathlessness } \\
\text { Wheezing }\end{array}$ & $\begin{array}{r}10 \cdot 0 \\
9 \cdot 6 \\
21 \cdot 6 \\
11 \cdot 7 \\
10 \cdot 1 \\
19 \cdot 5\end{array}$ & $\begin{array}{l}10 \cdot 5 \\
11 \cdot 2 \\
22 \cdot 3 \\
15 \cdot 9 \\
10 \cdot 0 \\
15 \cdot 8\end{array}$ & $\star$ & $\begin{array}{r}9 \cdot 9 \\
9 \cdot 6 \\
21 \cdot 5 \\
11 \cdot 7 \\
10 \cdot 0 \\
19 \cdot 5\end{array}$ & $\begin{array}{l}13 \cdot 5 \\
11 \cdot 7 \\
22 \cdot 5 \\
16 \cdot 2 \\
12 \cdot 0 \\
21 \cdot 7\end{array}$ & $\begin{array}{l}\star \star \\
\star \star \\
\star \star \\
\star \star \\
\star \star\end{array}$ \\
\hline $\begin{array}{l}\text { Physician's diagnosis (\%): } \\
\text { Asthma } \\
\text { Emphysema }\end{array}$ & $\begin{array}{l}4 \cdot 4 \\
0 \cdot 1\end{array}$ & $\begin{array}{l}4 \cdot 6 \\
0.5\end{array}$ & $\star$ & $\begin{array}{l}4 \cdot 4 \\
0 \cdot 1\end{array}$ & $\begin{array}{l}5 \cdot 7 \\
0 \cdot 2\end{array}$ & $\star \star$ \\
\hline $\begin{array}{l}\text { None of these symptoms } \\
\text { nor physicians diagnoses } \\
\text { SFEV } 1 \text { (mean (SD)) } \ddagger \\
\text { SFVC (mean (SD)) } \ddagger\end{array}$ & $\begin{array}{l}48 \cdot 8 \\
-0.44(0.95) \\
-0.20(0.94)\end{array}$ & $\begin{array}{l}42.4 \\
-0.75(1.09) \\
-0.74(1 \cdot 10)\end{array}$ & $\begin{array}{l}\star \star \\
\star \star \\
\star \star\end{array}$ & $\begin{array}{l}48 \cdot 7 \\
-0.47(0 \cdot 88) \\
-0.25(0.86)\end{array}$ & $\begin{array}{l}44 \cdot 1 \\
-0.88(1 \cdot 13) \\
-0.69(1.03)\end{array}$ & $\begin{array}{l}\star \star \\
\star \star \\
\star \star\end{array}$ \\
\hline
\end{tabular}

${ }^{\star} \mathrm{P}<0.05 ;{ }^{\star \star} \mathrm{P}<0.01$; for each variable comparing subjects with spirometric recordings within the set criteria to those outside the

criteria.

Includes 15 subjects with missing information.
$\ddagger$ See text for calculations of SFEV
and SFVC. Spirometry was missing in subjects with unacceptable recordings $(n=122)$ and $\ddagger$ See text for calculations of $\mathrm{SFEV}$
subjects who were unwilling to perform measurements $(n=8)$. 
Figure 2 Odds ratios with 95\% CIs for spirometric failure according to the 1983 and 1993 criteria from the European Community for Coal and Steel for each respiratory symptom in subjects with symptom in subjects with adjustment for age, height, weight, smoking, and marital status (categories as in table 3) ( $n=20$ 430). Subjects with missing information on any of the respiratory symptoms are excluded.

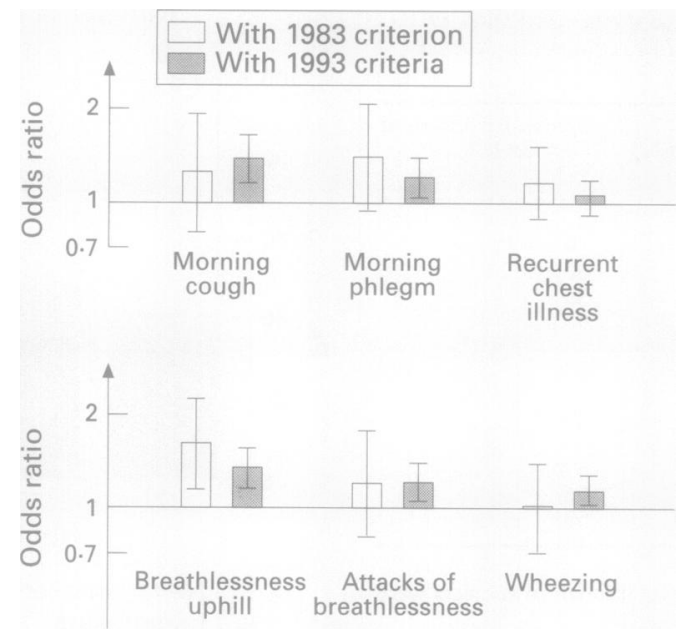

Spirometric failures were more prevalent in never smokers than in smokers and ex-smokers (table 2). The proportion of smokers and ex-smokers increased gradually with the number of acceptable recordings, from $32 \%$ (9\%) in subjects with no acceptable recordings to $44 \%(25 \%)$ in subjects with successful spirometry, whereas the proportion of never smokers decreased correspondingly (fig 1). Subjects with spirometric failure consisted of a larger proportion $(P<0.0001)$ of single men $(36 \%)$ than subjects with successful spirometry (17\%) (table 2).

The proportion of subjects with breathlessness uphill and a physician's diagnosis of emphysema was higher $(P<0.05)$ among subjects with spirometric failure than those within the criterion (table 2). Altogether $48 \%$ reported none of the six respiratory symptoms nor a physician's diagnosis of asthma or emphysema. This proportion increased gradually with the number of acceptable recordings, from $38 \%$ in subjects with no acceptable recordings to $49 \%$ in subjects with three suc- cessful recordings. Within each smoking group, failure rates were higher in symptomatic than in asymptomatic subjects. As expected subjects with spirometric test failure had a more negative $(P<0.01) S^{S F E V}$ and SFVC than those with successful spirometry (table 2).

Multiple logistic regression analysis was used to estimate the adjusted odds ratios (ORs) for 1983 spirometric failure after adjustment for age, height, weight, smoking, and marital status. Table 3 shows results from subjects with FVC values $\leqslant 6.001$ compared with the results from the 1993 criteria. The significant effects of smoking and marital status found in table 3 were also present in subjects with FVC values $>6.00 \mathrm{l}$ and in asymptomatic as well as symptomatic subjects. No significant first order interaction effects were found (no departure from a multiplicative model) from age, smoking, and marital status on the risk of 1983 spirometric failure (table 3). Additional analyses were performed after including a degree of airflow limitation $(\mathrm{FEV} / \mathrm{FVC}$ as a continuous variable) into the model. Although this additional adjustment reduced the regression coefficients from smoking and marital status by a maximum of $35 \%$ and $33 \%$, respectively, both variables remained significantly $(P<0.01)$ associated with 1983 spirometric failure.

A series of multiple logistic regression analyses were performed to estimate the adjusted ORs for 1983 spirometric failures associated with each respiratory symptom (fig 2). Only breathlessness uphill was associated with 1983 spirometric failure. This symptom remained significant $(P<0.05)$ after simultaneous adjustment for all other symptoms and a physician's diagnosis of asthma or emphysema, with an OR of 1.5 (95\% confidence interval (95\% CI) $1 \cdot 0-2 \cdot 2)$. No significant effects of first order interaction were found

Table 3 Spirometric recordings in $n(\%)$ with adjustedt ORs and 95\% CI outside the 1983 and 1993 criteria from the European Community for Coal and Steel in subjects with FVC $\leqslant 6.00 \mathrm{l}$ by age, height, weight, smoking, and marital status $(n=24826) \ddagger$

\begin{tabular}{|c|c|c|c|c|c|c|c|}
\hline & \multirow{2}{*}{$\begin{array}{l}\text { Total } \\
n\end{array}$} & \multicolumn{3}{|c|}{ Spirometric recordings outside the 1983 criterion } & \multicolumn{3}{|c|}{ Spirometric recordings outside the 1993 criterion } \\
\hline & & $n(\%)$ & OR $(95 \% C I)$ & $P$ value & $n(\%)$ & OR $(95 \% C I)$ & Pvalue \\
\hline \multicolumn{8}{|l|}{ Age (y): } \\
\hline $30-34$ & 6849 & $115(1 \cdot 7)$ & 1 & & $584(8.5)$ & 1 & $\star \star$ \\
\hline $35-39$ & 8402 & $129(1 \cdot 5)$ & $1 \cdot 1(0 \cdot 9-1 \cdot 4)$ & & $762(9 \cdot 1)$ & $1 \cdot 1(1 \cdot 0-1 \cdot 3)$ & \\
\hline $40-44$ & 8264 & $122(1 \cdot 5)$ & $1.2(0.9-1.5)$ & & $853(10 \cdot 3)$ & $1 \cdot 3(1 \cdot 2-1 \cdot 5)$ & \\
\hline \multicolumn{2}{|l|}{ Height $(\mathrm{cm})$ : } & $23(1 \cdot 8)$ & $1 \cdot 4(0 \cdot 9-2 \cdot 3)$ & & $136(10 \cdot 4)$ & $1 \cdot 3(1 \cdot 1-1 \cdot 6)$ & \\
\hline$<175$ & 6405 & $112(1 \cdot 7)$ & 1 & & $707(11 \cdot 0)$ & & $\star \star \star$ \\
\hline $175-179$ & 7551 & $107(1.4)$ & $0.9(0.7-1.2)$ & & $702(9 \cdot 3)$ & $0.8(0.7-0.9)$ & \\
\hline $180-184$ & 7050 & $111(1 \cdot 6)$ & $1 \cdot 0(0 \cdot 7-1 \cdot 3)$ & & $612(8 \cdot 7)$ & $0.7(0.6-0.8)$ & \\
\hline$\geqslant 185$ & 3820 & $59(1.5)$ & $0.9(0 \cdot 7-1 \cdot 3)$ & & $314(8 \cdot 2)$ & $0.6(0.5-0.7)$ & \\
\hline \multicolumn{8}{|l|}{ Weight (kg): } \\
\hline$<70$ & 4908 & $98(2 \cdot 0)$ & 1 & $\star$ & $467(9 \cdot 5)$ & 1 & $\star \star$ \\
\hline $70-79$ & 9347 & $120(1 \cdot 3)$ & $0.7(0.5-0.9)$ & & $806(8 \cdot 6)$ & $1 \cdot 0(0 \cdot 9-1 \cdot 1)$ & \\
\hline $\begin{array}{l}80-89 \\
\geqslant 90\end{array}$ & 6860 & $114(1 \cdot 7)$ & $0.9(0 \cdot 7-1 \cdot 2)$ & & $639(9 \cdot 3)$ & $1 \cdot 2(1 \cdot 0-1 \cdot 3)$ & \\
\hline \multirow{2}{*}{\multicolumn{5}{|c|}{ Smoking: }} & & & \\
\hline Never smokers & 7889 & $202(2 \cdot 6)$ & & $\star \star$ & & & 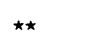 \\
\hline Ex-smokers & 6096 & $60(1.0)$ & $0.4(0.3-0.6)$ & & $504(8 \cdot 3)$ & $0.7(0.7-0 \cdot 8)$ & $a_{n}$ \\
\hline Smokers of $<15$ cigarettes a day & 4700 & $58(1 \cdot 2)$ & $0.5(0.4-0.7)$ & & $393(8 \cdot 4)$ & $0.8(0.7-0.9)$ & \\
\hline \multirow{2}{*}{\multicolumn{3}{|c|}{ Marital status: }} & $0.5(0.3-0.6)$ & & $589(9 \cdot 6)$ & $0.9(0.8-1.0)$ & \\
\hline & & $231(1 \cdot 2)$ & 1 & $\star \star$ & & & $\star \star$ \\
\hline Single & 4258 & $144(3.4)$ & $2 \cdot 7(2 \cdot 1-3 \cdot 3)$ & $x \times$ & $\begin{array}{l}1643(8 \cdot 6) \\
552(13 \cdot 0)\end{array}$ & $1.6(1.4-1.8)$ & $\star \star$ \\
\hline Divorced or separated & 1571 & $14(0.9)$ & $0.8(0.5-1.4)$ & & $140(8 \cdot 9)$ & $1.0(0 \cdot 8-1 \cdot 2)$ & \\
\hline
\end{tabular}

${ }^{\star} \mathrm{P}<0.05 ;{ }^{\star \star} \mathrm{P}<0.01$; for the independent variable in each multiple logistic model for spirometry failure

tAdjusted for age, height, weight, smoking, and marital status.

fIncludes all subjects after excluding 44 widowers and those with missing information on any of the covariables. 
from age, smoking, marital status, and breathlessness uphill. A high rate of spirometric test failure was found in a small number of subjects who reported a physician's diagnosis of emphysema $(n=27)$, but its OR of $3.6(95 \%$ CI $0.5-27 \cdot 0$ ) did not reach the $5 \%$ level of significance.

\section{CRITERIA}

In subjects with FVC values $\leqslant 6.001$ altogether $9.5 \%$ failed the 1993 criteria (table 2) and included subjects who failed either the FVC criterion (1.4\%), FEV criterion $(5 \cdot 2 \%)$, or both $(2.9 \%)$. Unlike the observations with the 1983 criterion, we found that five out of six respiratory symptoms were more prevalent $(P<0.01)$ in subjects who failed the 1993 criteria than in those who fulfilled them (table 2 and fig 2). The rate of failing the 1993 criteria increased with the number of respiratory symptoms from $9 \cdot 1 \%$ in subjects without any of the six symptoms to $14.7 \%$ in subjects with six symptoms. The number of respiratory symptoms defined as an ordinal variable (from 0 to 6 ) was a significant predictor $(\mathrm{P}<$ 0.001 ) for failing the 1993 criteria, with an OR of $1.6(95 \%$ CI $1 \cdot 3-2 \cdot 1)$ for six symptoms $v$ no symptoms.

The adjusted ORs for failing the 1993 criteria increased significantly with age and declining height (table 3 ). The significant effect of weight, found in table 3 , disappeared after excluding subjects with weight $\geqslant 90 \mathrm{~kg}$. As with the 1983 criterion, smoking and marital status were related to the 1993 criteria and remained so after additional adjustment for degree of airflow limitation.

\section{Discussion}

In this cross sectional survey of men aged $30-46$ years, only $1.6 \%$ failed the 1983 criterion which was used during data collection. Subjects who at the same time obtained recordings within the 1993 criteria did so without any additional testing. If the 1993 criteria instead of the 1983 criterion had been used during data collection, an additional $9.5 \%$ of the subjects would have needed further testing to fulfil the stricter criteria. As only the 1983 criterion was used during data collection, analyses should strictly be done with the 1983 criterion. When comparing the two criteria we found a selection of subjects who would need additional testing when the new criteria were used. Spirometric test failures with both criteria occurred more often in never smokers than in smokers and ex-smokers. Also older age, lower height, and excess weight were associated with failing the 1993 criteria.

Selection bias in attendance may have affected our results. All eligible subjects were invited to our survey and spirometry was performed consecutively at attendance regardless of demographic characteristics or answers given in the questionnaire. Although younger attenders were given priority over older attenders when queues developed at spirometry testing, the age composition of subjects who performed spirometry was identical to that in the total eligible population (table 1). The prevalence of smoking among attenders in our survey was identical to that found from a postal questionnaire in 1985 of men aged $30-45$ years ( $90 \%$ response) in the same area. ${ }^{14}$ The smoking specific prevalences of the different respiratory symptoms among subjects who performed spirometry in our survey who lived in Bergen are in accordance with findings from a postal questionnaire in 1972 of men aged $30-49$ years in an urban population of Norway. ${ }^{15}$ Thus, it is unlikely that the effects found of age, smoking, or respiratory symptoms on spirometric failure could be explained by selection bias alone.

Residual confounding by smoking or respiratory symptoms could have affected the relation between marital status and spirometric failure. This could occur if smoking habits or respiratory symptoms of an individual were reported differentially in single compared with married subjects. The observed higher spirometric failure rate in single compared with married men was also found in asymptomatic never smokers, which indicates that residual confounding by smoking or respiratory symptoms cannot explain this relation. The lower attendance rate in single men may indicate that they are less motivated to perform spirometry than married men. Being single may also be an indicator of poor general health ${ }^{16}$ and represent a marker of other correlated factors such as low socioeconomic state and low income. ${ }^{17}$ The relation between marital status and spirometric failure must be interpreted with caution as the non-response rate was higher in single than in married subjects.

In agreement with previous studies from both selected occupational groups ${ }^{45}$ and general populations ${ }^{18}$ we found higher spirometric failure rates in symptomatic compared with healthy subjects after adjustment for age and smoking. In a young adult office working population, spirometric failure was also more frequent in men with bronchial hyper-responsiveness than in non-responsive men. ${ }^{19}$ Furthermore, subjects with obstructive airways disease have greater variability in lung function than healthy subjects. ${ }^{6}$ These findings are consistent with increased bronchoconstriction after repeated forced expiration manoeuvres to a greater extent in symptomatic than in asymptomatic subjects.

Previous studies in men have found different effects from smoking on spirometric test failure. ${ }^{51819}$ Differences in population selection, age composition, amount of smoking, and presence of obstructive airways disease might explain some of these discrepancies. We found higher spirometric failure rates in never smokers compared with smokers and ex-smokers after adjustment for other covariables. Selection bias might be one explanation for this finding. Subjects with bronchial responsiveness would not take up smoking and smokers who develop bronchial responsiveness may tend to stop smoking. ${ }^{20}$ Another explanation might be that maximum expiratory flow is obtained at a lower intrapleural 
pressure in subjects with airflow limitation due to compression of the airways, ${ }^{21}{ }^{22}$ making more reproducible recordings in smokers compared with never smokers. To support this hypothesis, we found that the within subject SD from three recordings of $\mathrm{FEV}_{1}$ (FVC) were smaller $(P<0.001)$ in smokers than in never smokers, being 96 (95) and 102 (108) $\mathrm{ml}$, respectively. Consistent with this, we found that the protective effect of smoking on spirometric failure was reduced somewhat, but was still significant after adjustment for degree of airflow limitation. This apparent higher precision in spirometric recordings among smokers compared with never smokers may have been an artefact if smokers needed more expiration manoeuvres before acceptance than did never smokers. Thus, future studies should also include information on the number of spirometric attempts necessary to obtain three acceptable recordings.

With the 1993 criteria, we confirmed findings from the NHANES III study (with the same acceptability criteria). These are that shorter subjects with smaller lung volumes were more likely than taller subjects to obtain spirometric failure. ${ }^{23}$ For lung volumes $>21$ the 1993 criteria are based on a percentage difference between the two highest values of $\mathrm{FEV}_{1}$ and FVC. A percentage limit will give larger tolerance in taller subjects with larger lung volumes than in shorter subjects with smaller lung volumes. Therefore, a higher percentage of shorter subjects will be inappropriately classified as having a non-reproducible test. In contrast, taller subjects are less likely to fail the 1993 reproducibility requirement. The NHANES III study also found that the 1993 failure rates increased with age in adults from $2 \%$ failures in subjects aged $26-35$ years to $15 \%$ in those $>75$ years. Similarly, we found that increasing age increased the difficulty in fulfilling the 1993 criteria, although only men aged 30-46 years were included in our survey. This age effect disappeared after adjustment for lung volume. The $\mathrm{FEV}_{1}$ failure rate with the 1993 criteria in our survey $(8 \%)$ was identical to that in men aged 25-44 years in a community study in the United States with identical acceptability criteria. ${ }^{18}$ In men aged 22-44 years from an office working population, $15 \%$ failed the FEV $_{1}$ criterion. ${ }^{19}$ Their subjects consisted of $47 \%$ never smokers compared with $38 \%$ never smokers in our study.

We found that overweight was associated with failing the 1993 criteria. The component of weight due to adipose tissue was evaluated with BMI instead of weight as an independent variable. Heavy subjects (BMI $\geqslant 26.5 \mathrm{~kg} / \mathrm{m}^{2}$ ) had an adjusted OR of $1 \cdot 4(95 \%$ CI $1 \cdot 2-1 \cdot 7)$ for failing the 1993 criteria compared with light subjects $\left(B M I<22.5 \mathrm{~kg} / \mathrm{m}^{2}\right)$. Thus, obese men had more difficulty fulfilling the 1993 criteria in a sitting position than did thin men.

The inability to fulfil the acceptability and reproducibility criteria used during data collection should not be applied to reject these subjects, but rather should lead to the collec- tion of more than the minimum of three technically acceptable manoeuvres. ${ }^{3}$ Any attempt to improve the quality of measurements by excluding from analysis subjects with test failure will bias the study towards the null-that is, against showing the ill effects of any exposure under suspicion. ${ }^{24}$ Options are to include results of all subjects, whether or not they had test failures or to adopt more liberal criteria of reproducibility. ${ }^{18}$ Our findings suggest that the gain in precision of the spirometric recordings is rather small compared with the extra effort necessary from the subjects and technicians to fulfil the 1993 criteria instead of the 1983 criterion when performing epidemiological surveys in the general population. Further testing would also be time consuming and costly when conducting large general population surveys. Recent studies among patients with severe airflow obstruction have shown that higher values of $\mathrm{FEV}_{1}{ }^{25}$ and $\mathrm{FVC}^{26}$ were obtained with submaximal or relaxed expiratory manoeuvres. The ATS spirometry standards are currently under review for a new update. ${ }^{27} \mathrm{We}$ found that especially shorter and older subjects as well as those with chronic respiratory symptoms found it more difficult to obtain successful reproducible recordings when the 1993 criteria were used compared with the 1983 criterion. This could make it more difficult to assess changes in lung function over time in these groups of subjects. Our data suggest that the new 1993 criteria are unnecessarily strict to ensure adequate acceptable and reproducible spirometric recordings in general population studies. Further studies are needed to evaluate predictors of spirometric test failure with either of the two acceptability criteria randomly being used during data collection.

We acknowledge the staff at the National Health Screening Service for data collection and making the data file. We also thank S Nilssen for technical assistance. This survey was supported by grants from the Research Council of Norway, J E Isbergs fund and Confederation of Norwegian Business and Industry.

1 Quanjer PH. Standardized lung function testing. Bulletin Européen de Physiopathologie Respiratoire 1983;19(suppl

2 Society AT. Standardization of spirometry: 1987 update. Am Rev Respir Dis 1987;136:1285-98.

3 Quanjer PH. Standardized lung function testing. Eur Respir f 1993;6(suppl 16): 1-40.

4 Eisen EA, Oliver LC, Christiani DC, Robins JM, Wegman DH. Effects of spirometry standards in two occupational cohorts. Am Rev Respir Dis 1985;132:120-4.

5 Kellie SE, Attfield MD, Hankinson JL, Castellan RM. Spirometry variability criteria-association with respiratory morbidity and mortality in a cohort of coal miners. Am $\mathcal{f}$ Epidemiol $1987 ; 125: 437-44$.

6 Pennock BE, Rogers RM, McCaffree DR. Changes in measured spirometric indices-what is significant? Chest measured spirom

7 Laszlo G. European standards for lung function testing: 1993 update. Thorax 1993;48:873-6.

8 Becklake MR. Epidemiology of spirometric test failure. $\mathrm{Br} \mathcal{F}$ Ind Med 1990;47:73-4.

9 Bjartveit K, Foss OP, Gjervig T, Lund-Larsen PG. The cardiovascular disease study in Norwegian counties. Background and organization. Acta Medica Scandinavica (Supplements) 1979;634:5-70.

10 Cotes JE, Leathart GL. Lung function; assessment and application in medicine. Oxford: Blackwell Sci Publ, 1993

11 Humerfelt S, Gulsvik A, Skjærven R, Nilssen S, Kvåle G, Sulheim $\mathrm{O}$, et al. Decline in $\mathrm{FEV}_{1}$ and airflow limitation related to occupational exposures in men of an urban community. Eur Respir f 1993;6:1095-103.

12 Gulsvik A. Prevalence and manifestations of obstructive lung disease in the city of Oslo. Scandinavian fournal of Respiratory Diseases 1979;60:286-96. 
13 Dixon JW. BMDP statistical software manual. Berkeley: University of California Press, 1990.

14 Bakke P, Gulsvik A, Eide GE, Hanoa R. Smoking habits and lifetime occupational exposure to gases or dusts, including asbestos and quartz, in a Norwegian community. Scand $f$ Work Environ Health 1990;16:195-202.

15 Gulsvik A. Prevalence of respiratory symptoms in the city of Oslo. Scandinavian Fournal of Respiratory Diseases 1979 60:275-85.

16 Jacobsen BK, Thelle DS. The Tromsø heart study: responders and non-responders to a health questionnaire, do they differ? Scand $\mathcal{F}$ Soc Med 1988;16:101-4.

17 Tibblin G. A population study of 50 -year-old men: an analysis of the non-participation group. Acta Medica Scandinavica 1965;178:453-9.

18 Eisen A, Dockery DW, Speizer FE, Fay ME, Ferris BG The association between health status and the performance of excessively variable spirometry tests in a popumance of excessively variable spirometry tests in a population-based study

19 Nganga LW, Ernst P, Jaakkola MS, Gerardi G, Hanley $\mathrm{H}$, Becklake MR. Spirometric lung function Distribution and determinants of test failure in young adult population. Am Rev Respir Dis 1992;145: 48-52.
20 Bakke P, Baste V, Gulsvik A. Bronchial responsiveness in a Norwegian community. Am Rev Respir Dis 1991;143 317-22.

21 Hyatt RE, Flath RE. Relationship of air flow to pressure during maximal respiratory effort in man. $\mathcal{f}$ Appl Physiol 1966;21:477-82.

22 Davies C, Campbell EJM, Openshaw P, Pride NB, Woodroof G. Importance of airway closure in limiting maximal expiration in normal man. $\mathcal{f}$ Appl Physiol 1980;48:695-701.

23 Hankinson JL, Bang KM. Acceptability and reproducibility criteria of the American Thoracic Society as observed in a sample of the general population. Am Rev Respir Dis 1991;143:516-21.

24 Eisen E. Standardizing spirometry: problems and prospects. Occup Med 1987;2:213-25.

25 Krowka MJ, Enright PL, Hyatt JR. Effect of effort on measurement of forced expiratory volume in one second. $\mathrm{Am}$ Rev Respir Dis 1987;136:829-33.

26 Stoller JK, Basheda S, Laskowski D, Goormastic M, McCarthy $\mathrm{K}$. Trial of standard versus modified expiration to achieve end-of-test spirometry criteria. $\mathrm{Am} \mathrm{Rev}$ Respir Dis 1993;148:275-80.

27 Enright P. Can we relax during spirometry? Am Rev Respir Dis 1993;148:274. 